\title{
The Use of Social Media in Public Relations at Non-Governmental Organisations in South Africa
}

\author{
G. Nchabeleng, CJ Botha, CA Bisschoff \\ Work Well Research Unit, North-West University, Potchefstroom, South Africa \\ nchabelengmpumi@yahoo.com,Christoff.botha@nwu.ac.za,Christo.bisschoff@nwu.ac.za
}

\begin{abstract}
Social media can be a useful tool in public relations in non-governmental organisations (NGOs), but do NGOs make use of social media in their quest for service delivery in South Africa? Social networking sites, blogging, email, instant messaging, and online journals are some of the technological changes that changed the way interaction between people and how they gather information. Although social media is mainly used for interactive dialogue and social interaction, the private sector soon realised that the web-based technologies (especially Facebook and Twitter) could also be a competitive business tool. Non-governmental organisations (NGOs) soon followed suit however at a slower pace than the general communication growth rate of social media in South Africa. This article examines if social networking sites have any impact on public relations practices of NGOs in South Africa - an environment where both customers and employees still struggle to take full advantage of social media. The critical literature findings increase the understanding of the current and future challenges of social media use in public relations at NGOs in South Africa. The study explores the main differences between traditional and social media, how social media is redefining public relations role, and shed some light on defining public relations practices, identify the uses, limitations and benefits of social media by public relations practitioners in NGOs. Recommendations for future communication research are given. Based on the literature, a qualitative research design collected data using semi-structured, individual interviews. The results revealed that social media platforms such as Facebook do have an effect, and even changed the way in which NGOs communicate. The study also revealed that social media certainly has an impact on public relations relationships. This means that it has become crucial that public relations practitioners at NOGs embrace and take advantage of social media, and that they should also invest in proper electronic platforms to reap the benefits of improved communication internally and externally.
\end{abstract}

Keywords: Public relations, social media, traditional media, excellence theory, Grunig Hunt model

\section{Introduction}

In South Africa, various studies highlighted social media as a communication tool used by public relations, given that it is used appropriately and efficiently to address the challenges non-governmental organisations (NGOs) face. Primarily the service delivery challenges concern quality lack of reliability, confidentiality and privacy. The growing number of communication studies investigate and discuss the implication of innovation in social media usage (Kent \& Taylor, 2002; Waters et al., 2009; Curtis et al., 2010; Khan, 2017; Medaglia \& Zheng, 2017). The interpersonal mass media divide gains momentum from new media platforms that help to bridge and attract scholars who focus on examining the uses and effects of social media on various levels (Stoycheff et al., 2017). Governments around the world strategically use social media in multiple initiatives to co-produce public services, and they also incorporate external stakeholders (such as non-governmental organisations and citizens) in this service delivery exercises. Many social media characteristics have been identified. These are case blogs, microblogs (Twitter), content sharing (YouTube, Instagram), virtual communities, bookmarking sites; collectively these are known as social media platforms (Stoycheff et al., 2017). The common denominator between the characteristics is that social media is increasingly used to organising and manage tool collaboration between non-government organisations. Social media becomes increasingly integrated into several aspects of businesses. Graham and Dutton (2014), state that social media, globally, should focus on the driving forces behind the technology, and the relics of the Internet. New technologies evolved quickly as the concept of networked technologies gained value and more individuals and companies started to apply these technologies.

Global interconnectivity has rapidly increased following the rise and spread of social media. This epitomises the concept of Web 2.0, which was an adaptation of the World Wide Web. Web 2.0 saw the growth of cloud computing, wikis, crowdsourcing and most notably, social networking (Tech Target, 2017). Although social media and Web 2.0 are often confused and used interchangeably, the core of social media is embedded in the 
Web 2.0 concept as an application thereof. In practice, this means that social media is realised based on the Web 2.0 concept (Khan, 2017). More specifically, Cole (2018) states that social media is an online conversation platform that replaces more conventional communication methods. It also facilitates access to many people at the same time. Although NGOs were slow to adopt these new technologies, the use of social media in NGOs has increased since the introduction of technology in 2006. Adoption of social media at NGOs, however, remains problematic. In their study, the World Wide Worx (2010) has found that NGOs do participate in social media and that they access to new technologies creatively. They do so by participating in numerous online communities, educating these communities in the process, by teaching them new skills to use and also to gather information online on relevant issues of importance to the NGOs. NGOs also use social network sites as platform social support, network with stakeholders and to share creative ideas. Participating in platforms such as Facebook provides new methods for NGOs through which individuals can learn new media skills. The interconnectivity of the world is characterised by an influx of information sharing. With $49 \%$ of the world's population connected to the internet, a growing number of people use a social media platform of some kind (Internet World Stats, 2017). South Africa alone has over 21 million internet users as of 2016 (World Wide Worx, 2017). From the findings, this study identified some shortcomings in the NGO sector towards social media use.

Most participants indicated that limited resources in NGOs are problematic, there is insufficient money, and knowledgeable staff can severely hamper an organisation's ability to create and execute an effective social media campaign. Given the significant role that social media is playing in NGO activities; the researchers are understandably concerned whether these online communities have an impact on NGOs' relationships. This concern has prompted this research to investigate the uses, benefits and limitations of social media in public relations among NGOs in South Africa. Social media is defined as: "A group of intern-based applications which build on the ideological and technological foundations of Web 2.0. These applications allow the creation and exchange of user-generated content." Seargeant and Tagg (2014) also note that "connecting, sharing, commenting and creating relationships act as building blocks of social media." Regarding electronic communication platforms, Lubua, Semlambo and Pretorius (2017) highlight that social media is a communication platform where online communities can be created by users. Here they would share information in various formats. The findings revealed that there was a noticeable improvement in levels of sharing, connecting and commenting; however, social media is still not fully integrated into NGOs. The findings revealed that the central principle of social media is its ability to share information and content with other users. The content might be status updates; others subscribe to a profile to receive regular updates about new content. However, this study adopted the social media definition of Stoycheff et al. (2017) who state that: Firstly, social media consists of deinstitutionalised online platforms. This means that media companies and organisations do not create and disseminate the content.

Instead, they rely on the internet's decentralised sharing structures to do that. Secondly, social media consists primarily of user-generated content. This means that ordinary individuals create and disseminate media. Thirdly, Stoycheff et al. (2017) mention that social media is a dynamic environment that facilitates two-way interaction with an audience that is beyond the reach of any specific recipient. This is important from a branding or public relations point of view. In this regard, Cole (2018) states in support that social media platforms enable engagement with numerous customers in real-time too, for example, determine their needs, feelings or other information at any given time. This makes social media a valuable tool in business competitiveness. The use of social media globally continues to grow; this is also true in the public relations context. More platforms develop, and users join numerous platforms at the same time. Here Rouse (2016) states that the term social media is a collective term that refers to all online communications channels that are dedicated to community-based inputs, content-sharing, interaction and collaboration. Social media incorporates participation, collective intelligence collaborative creations and has borderless distribution characteristics. The uses of social media have added new dimensions to the old press. Here Reiman (2012:82) adds that "social media platforms differ from the traditional communications tools using its dependence on direct and indirect interaction with friends, followers, and constituents".

The use of these platforms shows similarities with the broadcasting industry, while the interactivity of social media transforms media messages into local and international dialogue forums (Al-Deen and Hendricks, 2012). Reiman (2012:8) further adds that users are demanding reciprocal relationships in social media 
groups they are subscribed to; therefore, they seek valuable two-way interactions. The realm of social media is a collaboration (Stokes, 2009:337); this is even more so today (ISPA, 2017). This article aims to create a landscape for a public relations communication strategy. This is important because the essential factors need to be identified when executing a social media strategy in public relations strategy in a non-governmental organisation.

\section{The South African Social Media Situation}

According to Statistics South Africa (2017) indicates that the total population of South Africa is 55, 21 million people; 66\% are urbanised. Some 28.6 million South Africans use the Internet and 15 million of them use social media platforms. Social media platforms like Facebook, Instagram and Twitter, have experienced high growth rates; Facebook announced that it has more than 1.32 billion active daily users and over 2 billion active monthly users. The objective of South Africa's National e-Strategy is to position South Africa as a significant role-player in Information and Communications Technologies development (ICT) (SA, 2017). In support, the South Africa's National Development Plan - Vision 2030 states that a single cohesive National eStrategy is needed to ensure ICT development in all sectors of the economy (SA, 2017). It is generally accepted that ICT development is indispensable in modern society and that it is an important growthcomponent of South Africa's economy. Technology is used in almost every aspect of the economy. It improves productivity using robots, efficient computer hardware and advanced software applications. The United Nations World Summit describes the information and communication technology infrastructure as key to compete in the global market and also to reduce the digital divide gap (UN, 2017). The South African Department of Communications (SA, 2018) agrees with the United Nations that South Africa is one of those countries that should roll out Internet services to its citizens because many South Africans do not have Internet access.

If they do not have the internet, they cannot use the internet, and therefore, they cannot benefit from the economic advantages it offers. An all-inclusive National Action Plan is required to position South Africa as a country that is ready to transition into a fully digital society (SA, 2017). Smartphones, according to World Wide Worx (2017), significantly expanded the South African internet space but the high cost of data remains a limitation to grow this user segment of 21 million users. In this regard, the expressed intention in The National Development Plan (NDP) to provide sustainable connectivity via a central broadband infrastructure is a priority in the quest to reduce existing inequalities in the society such as unemployment, access to services and poverty (Government Communications Information System (GCIS), 2013). The real challenge for government, however, is to ensure that the ICT goals are actually achieved (SA, 2018). One intention of the National Broadband Policy is to mobilise the capabilities, resources and energies in both the public and private sectors, and to activate the civil society to connect South Africans to the Internet so that they can communicate not only within South Africa but also across the continent and with the entire world. This policy aims to provide vision and a long-term strategy to act as a catalyst for broadband connectivity in South Africa. This policy postulates a considerable challenge to the public sector and the South African government has an important role to play to deploy the national broadband networks (SA, 2018).

The policy has to be implemented soon because, back in 2009, the need was already identified. The South African Government Gazette (SA, 2009) then identified three fundamental principles that should be addressed to establish the link between broadband access and economic growth: critical mass in broadband access in South Africa, affordable access to broadband, skills of users must be developed so that the demand for online services require optimal personal and business services. These broadband objectives would play a crucial role in promoting a South African information society. At the highest level, this policy adheres to the Constitution of South Africa by creating the digital age conditions "to improve the quality of life of all citizens and free the potential of each person". In so doing, it enables equality in the rights, privileges and benefits of citizenship, ensures freedom of speech and associates with the Bill of Rights (South Africa Broadband Policy, 2013a, SA, 2018). This also aligns with the declaration of the Human Rights Council of United Nations General Assembly who stated that access to the internet is a basic human right because it enables individuals to "exercise their right to freedom of expression" (SA, 2013b:2). The South Africa Broadband Policy reflects the commitment of the South African Government to constitute an enabling environment. 
The Current Status of Social Media and NGOs in South Africa: A study by the South African Social Media Landscape (2018) indicates that South African Facebook users grew by 14\% since 2016 (from 14 to 16 million). Of these, 14 million access social networks on their mobile devices. More recently, World Wide Worx (2017) reports that South African Internet users grew to 21 million by the end of 2016, and approximately 22.5 million in 2017. Pillay (2017) writes that Facebook remained the most popular social network in South Africa. One in five South Africans uses Facebook. However, new statistics show that there are now more than one in five Facebook's users in the country (SA, 2018), and share this view by stating that Facebook is the social media of choice and has 1.9 billion users monthly with millions more joining every month Facebook has evolved from a small student age group network to a global site. Telecommunications laws are governed by the Ministry of Communications in South Africa. The minister administers, regulates and enforces the Telecommunications Act (No. 103 of 1996) (SA, 1996) and Electronic Communications Act (No. 36 of 2005) (SA, 2005) using the industry regulator ICASA (Thornton et al., 2010:101).

These acts require every service provider of a telecommunications service to be interconnected via his or her telecommunication system (except is such a request is deemed unreasonable) (SA, 1996; 2005). Other regulating bodies in the telecommunications system include the competition commission (who oversees the fairness of competition between all the industries) and the justice department who resolves disputes and legal issues within the telecommunications sector (ISPA, 2018). The telecommunication sector plays a significant role to drive and enable the new growth and development in the country. Against this background, the results show that the South African telecommunication sector is establishing rules of good practice. The business (and private individuals) are also evaluating the full impact that social media have on service delivery, and while the NGO's are still not fully transformed, there is a growing awareness of the value to use social media in service delivery. They, however, seem to still lack the knowledge and confidence to use social media effectively and efficiently for professional service delivery. Soon this knowledge will become a required essential skill for public relations in NGOs in South Africa.

Purpose: This paper reviews and brings together the key findings of the literature to increase understanding of current and future challenges presented by social media to public relations in NGOs in South Africa. The purpose of this article takes a broad look at the main differences between traditional and social media to give an in-depth understanding of these types of media. Some light is also shed on defining public relations and normative models of public relations practices. This article further discusses the Grunig and Hunt two-way symmetrical model and some of the impact that these new forms of communication have had on public relations practitioners, especially in South Africa. This article aimed to review current published literature on social media and to identify the uses, limitations and benefits of social media for public relations practitioners employed in NGOs. The article also aims to identify existing gaps and to identify potential areas for future research in social media communication.

\section{Research Methodology}

A qualitative research design was selected to investigate the perceptions and processes when social media are used by public relations professionals. The systemic grounded theory was used to determine a general explanation of the procedures and interaction among people (Field, 2009). Furthermore, the epistemological foundations employed were constructionism and constructivism. This article empirically investigated the social media guidelines for public relations in non-governmental organisations.

Research Settings and Participants: The research was performed in the Gauteng province in South Africa. It investigated participants who could contribute to building the opening and axial coding of the theory in nine non-governmental organisations (NGOs) of varying sizes. In a grounded study the researchers chose (Field, 2009). Emails were sent to the selected NGOs to gain permission to research the NGOs. By nature, the organisational settings differed from participant to participant. Two types of non-probability sampling were used, namely snowballing and purposive sampling. Salmons (2015), defines purposive sampling as intentionally selected respondents to interview based on the needs of the study. Babbie and Mouton (2011), state that the most commonly used method in qualitative research is probability sampling. Dahl (2018) characterises social media as the democratisation of information, transforming people from content readers into publishers, the shift from broadcast one to many between people. 
Data Collection: Personal interviews were conducted and all the interviews were recorded. The researcher specifically observed how participants relate to their experiences on social media. Before conducting the semi-structured interviews, participants were assured of confidentiality. Permission to record the interviews were also obtained. The interview schedule was drafted and before semi-structured interviews were conducted with selected practitioners in the selected NGOs. The interview schedule allowed respondents to share a particular story if they wanted to do so without imposing some time limit. Each interview started with an initial question to prompt the participants to start explaining how they would apply social media to their public relations activities in NGOs. The interviews were held as informal conversations to create a relaxed environment where participants freely shared their experiences. As a result, the emerging stories provided useful insight into their experiences.

\section{Results}

The results create a fertile landscape for public relations practitioners in NGOs by providing holistic, logical and comprehensive structured central themes of social media attributes in public relations. These results were documented and classified after the interviews were conducted with the participants. The table firstly presents the identified communication categories experienced by public relation offices at NGOs then expands these categories in themes. The table also shows the notable quotes about these categories and themes to enhance better understanding of the themes' content.

Table 1: Key Social Media Attributes Experienced by the Public Relations Practitioners in Using for Communication in NGOs

\begin{tabular}{|c|c|c|}
\hline Category & Theme & Significant quote \\
\hline $\begin{array}{l}\text { Global } \\
\text { perspective }\end{array}$ & $\begin{array}{l}\text { 1. Immediate feedback } \\
\text { 2. Two-way } \\
\text { communication } \\
\text { 3. Convenient } \\
\text { 4. Easy to use }\end{array}$ & $\begin{array}{l}\text { 1. Social media has changed the way people communicate. } \\
\text { 2. It has the potential to educate, inspire, and engage others. } \\
\text { 3. Social media is informing and educating the public about } \\
\text { issues, to publish activity information or call people's } \\
\text { attention to the NGO. } \\
\text { 4. Public relations practitioners participate in formal and } \\
\text { informal communities or information and support } \\
\text { networks where information is exchanged. } \\
\text { 5. Participants share their experiences of NGOs to benefit } \\
\text { other activities, thereby creating information that is } \\
\text { discovered and used by other communities. } \\
\text { 6. Public relations engage with information online to learn } \\
\text { how to care for their NGOs and to deal with the practical } \\
\text { aspects of challenges, as well as to realign their } \\
\text { communication strategies to match the reality. }\end{array}$ \\
\hline $\begin{array}{l}\text { Success and } \\
\text { understanding } \\
\text { of social media }\end{array}$ & $\begin{array}{l}\text { 1. Communication } \\
\text { enabler } \\
\text { 2. New supporters } \\
\text { 3. Collaboration tool } \\
\text { 4. Organisation } \\
\text { promotion } \\
\text { 5. Fundraising } \\
\text { 6. Responsiveness } \\
\text { 7. Transparency } \\
\text { 8. Community } \\
\text { engagement }\end{array}$ & $\begin{array}{l}\text { 1. Social media provides information on a range of issues, } \\
\text { informing and educating the public about NGO activities. } \\
\text { 2. Social media provides information on mission, history and } \\
\text { organisational structure. } \\
\text { 3. Social media encourages and facilitates dialogue between } \\
\text { PR and public on donations and fundraising. } \\
\text { 4. Through social media, we have been able to talk with } \\
\text { other NGO members online, collect information get } \\
\text { experiences and opinions about a subject. } \\
\text { 5. Social media is used to form networks, to promote, } \\
\text { educate, and the campaign. }\end{array}$ \\
\hline $\begin{array}{l}\text { Purpose } \\
\text { Benefits }\end{array}$ & $\begin{array}{l}\text { 1. Enhancing } \\
\text { Relationships } \\
\text { 2. Knowledge sharing } \\
\text { 3. Easy communication } \\
\text { 4. Technology } \\
\text { discovery }\end{array}$ & $\begin{array}{l}\text { 1. Social media is more available are anonymity, engagement } \\
\text { and connectedness. } \\
\text { 2. Increased interactions with others. } \\
\text { 3. Social media helps promote NGOs' image, programs and } \\
\text { services they offer to the community, such as social and } \\
\text { emotional support. }\end{array}$ \\
\hline
\end{tabular}


5. Networking

6. Peer-to-peer communication

7. Transparency

8. Organisation promotion

\section{Challenges and disadvantages}

Social media Traditional media and influence traditional media

Social media platforms used

$\begin{array}{ll}\text { Impact of } & \text { Reach of social media } \\ \text { social media } & \end{array}$

The role public relations play in NGOs

1. Lack of:

- understanding

- resources

- open communication

- embracing social media

- skills

2. Non-secure platforms

3. Infrequent use

4. Technological change

5. Reputational risk

6. Internet and email use policy

7. Comprehensive 'how to guide' to set up accounts online resistance to change

1. Facebook

2. Google

3. Newsletter

4. Twitter

6. LinkedIn social media

1. Easier to do research

2. New communication channel

3. The high speed of communication

4. Need to keep up with new technology

5. Different writing style

6. New skills needed
4. Benefits of social media for NGO increase accessibility and widening access to NGO information.

5. Social media is used to increase funds, volunteers or community engagement.

6. The benefit of social media for NGO increase content and tailored information through newsletters, images or videos potential to influence policy and increase interactions with others.

1. Social media is informal, and people talk freely, this way they hide behind the screen, there is no hierarchy, they are in the comfort zone to express their feelings and attitudes.

2. You lose face-to-face contact with people.

3. Social media can be a communication channel where skills and interest can be identified because people may share more about themselves, but lack reliability.

4. Threatened by new technology, fear of the unknown, risk of disclosing personal private information online.

5. Quality concerns of social media information.

6. Lack of confidentiality and privacy impact on reputation.

7. The risk associated with communicating incorrect, harmful information online. Social media is seen as a possible waste of time.

8. Too much information on social networking site NGOs can't handle the volume, not sure how to correctly apply information found online.

9. Not sure which specific social media technologies are effective to use in NGO for behaviour change.

1. Social media is less hampered by time and space.

2. Anyone anywhere can participate in a discussion. Social media is a more effective way to spread the message.

3. Through social media, we encourage different stakeholders to attend events and participate in campaigns.

1. We use Facebook to stay in touch with friends, meeting new people, organising events, communicating with the internal and external publics.

2. We use Facebook to disseminate and improve communication for future project strategic planning.

3. We use Google and email often as it is friendly to use.

1. Social media allows the practitioner to stay up-to-date with trends and new developments in technology.

2. You can reach a large number of people at low cost via social media e.g. Facebook, email, Blogs and others.

3. The speed of communication emerged.

1. We understand the role of public relations practitioner as organising events, exhibitions, gala evenings.

2. The internet has added another communication channel to PR tools.

3. Public relations ensure that they generate publicity such as writing press/media releases

4. Writing articles for the organisation's publications (internal and external) audience.

5. We understand the role of a public relations practitioner's task as keeping media clip (articles that appeared in the media about the organisation). 
6. New skills needed in managing fear and expectations of online media.

7. We also ensure we establish a positive image of the organisation.

8. Managing the implementation of corporate/NGO communication.

The following themes were derived from the research findings of this research. These themes reflect how public relations practitioners in NGOs embraced social media in their organisations and are discussed below.

Theme 1: Global Perspective: Merrian-Webster (2018) reports that social media is best understood as communication using new kinds of online media which share the following characteristics: participation, openness, conversation, community and connectedness. The search findings redefined the belief that there was no transformation in NGOs towards using social media as a public relations tool. It showed that social media tools had transformed the public relations function in NGOs. During the interviews, different viewpoints and opinions regarding global perspective were voiced. On the one hand, participants positively indicated that social media made it easier to disseminate information to the public and to do research. On the other, some participants reported that it was difficult to use and understand social media; they cited it was tough to keep up-to-date with the ever-changing online technology. Furthermore, participants were enthusiastic about social media platforms such as Facebook, had facilitated access to information and helped them prepare and conduct successful campaigns.

Theme 2: Success and Understanding of Social Media: The participants indicated that they understand social media as a tool for sharing content, insights, and news. According to the participants, social media is a tool to reach the population, in particular, the youth via mobile phone devices. As an NGO, reaching the youth is of vital importance to ensure that youth get involved in NGO activities. This research finding is confirmed by Cole (2018) who observed that social media is an extra way of talking to your customers and clients in different forums where they are hanging out. Furthermore, Cole (2018) states that networking 24/7 is helpful if your prospects or clients even if they are in another time zone. Although there is no South African time difference, crucial information such as load-shedding, for example, can be disseminated by communications even after-hours and out of normal operating hours. The role of social media is to ensure that the NGO message is understood and to provide information about the NGO mission and objectives and to communicate and engage with diverse stakeholders.

Theme 3: Purpose and Benefits of Social Media: Social media is less restrained by space and time (Stokes, 2009). The interviews revealed that the biggest advantage of new media technologies is that it offers people the ability to assemble and to communicate with various individuals over a distance. They do so inexpensively. The participants indicated connecting and communicating with another person over distance gives the NGO an opportunity to be in contact with different stakeholders and enable them to deliver services without physical contact. The results also showed that the participatory value is a huge benefit of using social media and that it can easily reach different stakeholders. These benefits of social media are confirmed by Cole (2018) who indicates that if a service is free, once can easily attract large audiences; social media as a communication tool is basically free, easily accessible and it can be used alongside the traditional methods of public relations and communication. One can quickly engage with one's customers and have a visible web presence where real-time feedback can be generated.

Theme 4: Challenges and Disadvantages of Social Media: According to Fitch (2009), the Internet is a Wild West scenario, where anything goes, there are no rules, emphasising the unregulated and largely unmanaged practices of social media. The research showed the disadvantages have occurred in the form of negative or defamatory comments on the social media NGO site since it is open to everyone, it is easy to post and comment on online. The NGO has no control over what is said on social media pages. The problem is that anyone can join these sites and anyone can comment and partake in a discussion. For South Africa, many rural areas do not have social media access for example, and although the government through the National Development Plan (NDP) project is trying to address the ICT situation, the NGO sector cannot truly measure the impact of how people use social media and participate in campaigns. Another challenge indicated by the 
participants is that social media was making public relations roles more time-consuming. Participants admitted that it is difficult to manage the online activities along with their PR responsibilities. From the interviews, participants indicated the older practitioners were not as comfortable with using technology as the younger generation. Challenges they have were identified as uneasiness and feeling threatened by technology.

Theme 5: Social Media Influence Traditional Media: Numerous studies (Scott, 2010; Rajendran \& Thesinghraja, 2014; Azimi, 2016) indicate that the use of social media as a communication tool has not only provided an additional channel to traditional media but also strongly influences and complements traditional communication media. These observations were supported by the research participants indicating that social media provided public relations with new communication tools. Here Scott's (2010) view is that social media has revolutionised public relations communications by reducing dependence on print communications. Social media is also quicker and less expensive than print media because it eliminates the printing process. Also using a social media platform in conjunction with traditional media gives the organisation exposure and increases more chances to get a message out and impact on how the public receives it. According to the participants, the most important benefit for NGOs for using social media is that they now have access to more people, especially to people who previously might not have been reached by traditional media.

Theme 6: Social Media Platforms Used in NGOs: From the research findings, it was evident that the Internet had changed public relations functions at NGOs. During the interviews, the different views and opinions regarding the preferred platforms were voiced. On the one hand, participants positively indicated that social media platforms made it easier to do research and surveys among the customer base. They also acknowledged the ease of accessing information on websites. On the other hand, some participants were sceptic about the idea of loss of control over information.

Theme 7: The Impact of Social Media: The impact of social media had surpassed traditional media and easy access via mobile phones further supports social media as modern communication platform (Rajendran \& Thesinghraja, 2014:612). From the research, it was evident that the impact of social media was that the Internet had changed the practice of public relations, increased opportunities and had given rise to new skills and ethics. The participants also indicated that the impact of using social media lies in its participatory value and its ability to reach individuals. Although public relations are not always using it to its full potential, the opportunity still exists (Breakenridge, 2012). The speed of communication emerged as one of the most dominant themes with eight participants in NGOs agreeing that the most significant impact of social media was that it made communication instantaneous. Furthermore, social media immensely facilitate bringing together geographically dispersed individuals who share common interest or opinion.

Theme 8: The Role of Public Relations: Public relations are the two-way communication used by public relations practitioners to interact directly with key publics, to relay information to the community and also to members of the management team (Agile PR Solutions, 2018). This view is also supported by Kotler and Armstrong (2017) who further suggest that public relations are a management function that seeks to establish and maintain mutually beneficial relationships between an organisation and the public on which the success depends. As a result, public relation is a valuable marketing tool to manage noteworthy information for any organisation. The search findings revealed that public relations need to adapt their writing style and have technical skills to implement online plans.

Discussion of Results: The primary characteristics of social media, as mentioned in Table 1, are Global perspective, Success and understanding of social media, Purpose and benefits of social media, Challenges and disadvantages of social media, Social media influences traditional media, Social media platforms used in NGOs, Impact of social media and the Role of public relations. The characteristics are discussed next. From the global perspective, the research findings in this study found that social media is a unique communication tool. Social media is a powerful tool which offers collaboration between users and is a social interaction channel for a range of individuals. Studies (Chawinga, 2017; Khan, 2017, Lumbua, Semlambo and Pretorius, 2017) acknowledge an increase in social media as a powerful tool in human activities. A Botha, (2017) study confirms social media, Facebook and similar sites are becoming a communication tool used by businesses. 
Uyenco (2017) concurs and indicate that social media has become an effective tool for customer service, engagement, content creation, marketing and market research.

The study by Zang, Feng and Chen (2018) adds to this view by stating that social media is, in addition to providing content to an audience, also an interactive platform to facilitate dialogue. This supportive view is confirmed by Uyenco (2017) who stated that social media as a tool and as a platform is no longer isolated to the marketing or public relations team as social media affects several sectors. Cole (2018) states that social media also affects brand awareness (personal or business brand awareness) and facilitates networking or building online relationships. Networking and brand building are synergetic because, by networking, the brand is also becoming more visible. However, the study acknowledges the need to integrate social media in their day-to-day operations. From a managerial perspective (understanding, purpose and benefits), the research findings identified social media is becoming increasingly more important to disseminate information and to engage with customers. Social media provides the opportunity for practitioners in NGOs to engage the public in online platforms. This observation agrees with other studies, Botha (2017); Khan (2017) who highlighted the following factors to be important characteristics in enabling users to use social media in the companies comfortably. Social media can increase awareness, to advertise product or services, for business to business purposes, to gain feedback from customers, to analyse the competition in the industry and offer promotional offers or items on social media. Khan (2017) emphasises that understanding social media critically means, among other things to engage with the different forms of sociality on the Internet in the context of society.

On the contrary, regardless of the negative experience that users of social media may have experienced, a well-planned use brings positive benefits to social society and the NGOs (Lubua et al., 2017). The research findings in this study indicate that because the social media landscape is continually changing through innovation, Internet users are increasing on a daily basis, and new users are more vulnerable to security concerns because they have less experience and low knowledge. This observation agrees with other studies which concluded that security was a concern, but it is important to educate users about important security issues to build confidence on these platforms (Lubua et al., 2017). Unforeseeable trends, businesses and NGOs will need a devoted social media department to succeed on these platforms. The research finding is confirmed by Uyenco (2017) who observed that a department devoted to the discipline of social media would actively watch for these changes, anticipate them and even capitalise on them. These two studies emphasise that to control or guide the image online, in general, the strategies people use to achieve this are updating their status, sharing special events, posting comments, and or retweeting other posts frequently. The research findings stressed the challenge of NGO accessibility to social media, internet or technology and sometimes the origin information on social media. This finding is in line with the findings obtained by Botha (2017), namely that there is a challenge especially with customers who stay in rural areas. The Botha (2017) study also concluded that there is a challenge with unauthentic posts on social media platforms which can cause harm to the company's reputation.

Furthermore, another challenge that was mentioned was the fact that companies do not have face-to-face encounters with customers when using social media. The study discussed above confirms that social media can be utilised effectively and to the benefit of companies, depending on the techniques, strategies and frameworks that a company chooses to apply. Research findings suggest the need for understanding social responsibility and ethics of social media as a set of well-defined principles which govern the ways of communication taking place between the practitioner and the public. The principles are moral values that are important to a business. It is important that the practitioners present themselves truthfully on social media platforms. The research findings are confirmed by Stoycheff et al. (2017) who observed that personal integrity is part of a practitioner's professionalism. This implies that practitioners should never misrepresent, falsely promise or lie about products or services online as they are judged by the way they act. The principle of ethics is also confirmed by Uyenco (2017) highlighting that a social media practitioner that embraces ethical principles will be an asset to any business. This observation agrees with other studies (Botha, 2017) which concluded that there are general problems that a company encounter when using social networks. Botha (2017) further highlights reputation damage, when the wrong content which can be placed unintentionally on social media can damage a company's reputation. Ownership of user-generated content, employees are usually appointed and responsible for creating content. This will then carry the responsibility 
of approving content created before it is published on a social network site. The research findings also identified that most NGOs interviewed for this study do not have a technology plan in place.

Social media has an impact on behaviour change, and currently, NGOs struggle to find a balance based on the consequences of not employing technology effectively in the organisation. The research finding is also confirmed by the Han and Myers (2018) study indicating that these business applications of social media are considered innovative from a technology commercialisation perspective, but they can be very confusing to users who just want to use an SMS or social media to keep in touch with friends and families. The study also observed that social media might provide highly interactive platforms for users, so the needs of users are changing. On the contrary, other reasons why the company does not make use of social media platforms. What response was keeping up with social media trends can often distract a company from the core function of the business. Still, following traditional ways and return on investment is too little in the NGO sector. This observation is supported by the Botha (2017) study which concludes that if social media is not used efficiently, security is not efficient enough, which can lead to being hacked and cause reputational damage on the perceived relevance or usefulness of social media.

This study also determined the perception of respondents on how relevant social media in NGOs is in South Africa. The results in table 1 revealed that $70 \%$ of respondents are positive that social media is relevant in promoting the NGO activities. Specifically, the connectivity of social media plays a role in this positive view. Social media is readily available and affordable to many NGO practitioners. This observation agrees with other studies which concluded that social media could facilitate and reach specific audiences internationally on specific issues, and improve long-term, cost-effective relationships with supporters, volunteers, sponsors and donors regarding NGO activities (Chawinga, 2017, Lubua et al., Zoonen, Veerhoeven and Vleigenthart, 2017).

\section{Conclusion and Recommendations}

This study has concluded some shortcomings of social media use in public relations efforts of NGOs; hence the followings recommendations are made: Research should be conducted as there is a need to determine the relative effectiveness of the different types of social media platforms as networking sites for public relations communication. Research review is required to establish whether social media improves public relations communication practices in the short- and long-term. Further research would allow a better understanding of new public relations information experience and would particularly be useful to practitioners in NGOs who work with diverse publics regarding understanding how to connect with and inform public in social media. Research should be conducted to determine the impact that social media has on public relations in NGOs with large sample sizes. Furthermore, research should be undertaken to determine the longer-term impact on the effectiveness of social media for public relations using a mixed motive model or longitudinal studies. Geyer and Krumay (2015) mention that more research is needed about social media use in organisations and how companies can evolve their communication on social platforms, what are the standard best practices (for example successful applications), and how do organisation structures have to adapt. The findings showed that each of the studied variables existed in different levels among public relations in NGOs.

Continued research should be conducted by relevant communication departments (Public relations, Marketing, Government Communication Information Systems) to increase awareness and understanding of the current and future challenges of social media that the country still experiences. Further research in this area of social media would allow a complete understanding of new users' experiences and would be particularly useful to practitioners who work in NGOs in understanding how to connect and inform stakeholders in social networks. Public relations and NGOs management should develop and implement strategies and plans to effectively make sure that government should investigate the risks arising from using social media networks, such as sharing information online and the consequences for confidentiality and privacy. The government should strive to become a world leader in ICT. The government should develop mechanisms to educate the risk to assure users of their confidentiality and privacy effectively. The government should effectively address social media regulation, fake news into mainstream media. The benefits of social media should be promoted instead of making irresponsible threats to media and disturb internet freedom in South Africa. The necessary support system for the NGOs should be designed, developed and sustained by the government. NGOs should understand social media have the knowledge and confidence 
to use it appropriately and effectively in public relations, while their practitioners should become skilled so that they can include social media in their communications skills toolkit.

Summary: For the foreseeable future, social media is here to stay, and it will continue to evolve and grow in unprecedented ways. If an NGO business hopes to create and maintain a social media presence and increase their brand awareness and return on investment, public relations practitioners will need capable staff. Practitioners not only need the skills in NGOs, but also a level of insight that will ensure that they recognise opportunities and avoid challenges before they arise on social media platforms. Moreover, the variables resulted in a significant difference in the adoption, uses, purpose, benefits, impact and role of applying social media among public relations in NGOs. The study concludes that NGOs have the opportunity to improve their use of social media, through offering easy ways to use platforms, encourage sharing of the information useful in the NGOs and safeguard the security of the online platforms. The extended use of social media will enable practitioners to overcome challenges in NGOs with the possibility of improving NGO activities. Proper guidelines and policies should add to awareness, adoption, social responsibility and a positive organisational culture of social media as a valuable public relations tool in South African NGOs.

\section{References}

Agile PR Solutions. (2018). Public Relations Management Roles.

Al-Deen, H. S. N. \& Hendricks, J. A. (2012). Social Media Usage and Impact, Lexington, KY: Lexington.

Azimi, O. (2016). The Impacts of Social Media on Traditional Broadcast and Print Journalism.

Babbie, E. \& Mouton, J. (2010). The Practice of Social Research, Cape Town: Oxford University.

Botha, L. (2017). Utilising Social Media to the Benefit of Companies, Dissertation in Computer Science: NorthWest University

Breakenridge, D. (2012). Social Media and Public Relations: Eight New Practices for the PR Professionals, Upper Saddle River, NJ: Pearson Education.

Chawinga, W. (2017). Taking Social Media to a University Classroom: Teaching and Learning using Twitter, blog. International Journal of Education Technology in Higher Education, 14(3), 1-19.

Cole, L. (2018). Marketing with Social Media: 10 Easy Steps to Success for Business, Sydney: Wiley.

Curtis, L., Edwards, C., Fraser, K. L., Fudelsky, S., Holmquist, J., Thornton, K. \& Sweeter, K. D. (2010). Adoption of Social Media for Public Relations by Non-Profit Organisations. Public Relations Review, 26(1), 9092.

Dahl, S. (2018). Social Media Marketing, Theories and Applications, Thousand Oaks, CA: Sage Publications.

Field, A. (2009). Understanding statistics using SPSS, London: Sage.

Fitch, K. (2009). Making friends in the Wild West: Singaporean Public Relations Practitioners' Perceptions of Working in Social Media. Prism, 6(2).

Geyer, S. \& Kruman, B. (2015). Development of a Social Media Maturity Model - A Grounded Theory Approach. Proceedings of the 48th International Conference on System Sciences, IEEE Computer Society. Washington, DC, 5-8 January.

Internet Service Provider Association. (2018). ISPA. https://ispa.org.za/

Kent, M. L. \& Taylor, M. (2002). Beyond Excellence: Extending The Generic Approach to international Public Relations the Case of Bosnia. Public relations review, 33(1), 10-20.

Khan, G. F. (2017). Social media for Government, Singapore: Springer.

Kotler, P. \& Armstrong, G. (2017). Principles of Marketing, (17th ed.), Upper Saddle River, NJ: Pearson.

Lubua, E. W., Semlambo, A. \& Pretorius P. D. (2017). Factors Affecting the Use of Social Media in the Learning Process. South African Journal of Information Management 19, 1-12.

Medaglia, R. \& Zheng, L. (2017). Extending Impact Analysis in Government Social Media Research: Five Illustrative Cases. $18^{\text {th }}$ Annual International Conference on Digital Government Research. Staten Island, NY, 7-9 June.

Merrian-Webster. (2018). Online Dictionary.

Pillay, A. (2017). Exploring Alternative Revenue Sources that can be Utilized to Improve Advertising Revenue at SABC Public Broadcasting Radio Stations. Durban: Durban University of Technology.

PPC. (2015). PPC Integrated Report, Sandton: Merril Lynch (SA).

Rajendran, L. \& Thesinghraja, P. (2014). The Impact of New Media on Traditional Media. Middle-East Journal of Scientific Research, 22(4), 609-616. 
Reiman, C. (2012). Public Interest and Private Rights in Social Media. Oxford: Chandos.

Rouse, M. (2016). What is Social Media? https://whatis.techtarget.com/definition/social-media.

Salmons, J. (2015). Doing Qualitative Research, Singapore: Sage.

Scott, D. M. (2010). The new rules of marketing and PR, Hoboken. NJ: Wiley.

Seargeant, P. \& Tagg C. (2014). The Language of Social Media: Identity and Community on the Internet, New York, NY: Palgrave McMillan.

South Africa. (1996). Telecommunications Act (No. 103 of 1996), Pretoria: State Printers.

South Africa. (2005). Electronic Communications Act (No. 36 of 2005), Pretoria: State Printers.

South Africa. (2009). South African Government Gazette, Pretoria: State Printers.

South Africa. (2013). South Africa Broadband Policy.

South Africa. (2013). South African Government Gazette, Pretoria: State Printers.

South Africa. (2017). The Government Gazette Republic of South Africa, 629 (41242), Pretoria: State Printers.

South Africa. (2018). The South African Department of Communications. https://www.doc.gov.za/

South African Social Media Landscape. (2018). The2018 Social Media Landscape in South Africa.

Statistics South Africa. (2017). South Africa has 55 million Internet Users.

Stokes, R. (2009). E-Marketing: The Essential Guide to Online Marketing. $2^{\text {nd }}$ ed. New Delhi: Shumani.

Stoycheff, E., Liu, J., Kunto, A., Wiibowu. \& Nanni, D. P. (2017). What was learned about social media by studying Facebook? A decade in review. The American Journal of Nursing, 117(9), 50-54.

United Nations. (2017). 5 Tips for your Social Media Strategy.

Uyenco, K. (2017). The new social: How social media is changing the job market.

Waters, R. D., Burnett, E. M., Lamm, A. M. \& Lucas, J. (2009). Engaging stakeholders through social networking: How non-profit organisations are using Facebook. Public Relations Review, 35, 102-106.

World Wide Worx. (2010). Internet World Stats for 2010. www.Worldwideworx.com

World Wide Worx. (2017). Internet World Stats 2017. www.Worldwideworx.com

Zang, D., Feng, X. \& Chen, P. (2018). Social Behaviour and Personality. Social Behavior and Personality: An International Journal, 46(4), 667-681.

Zoonen, W., Veerhoeven, W. R. \& Vleigenthart, M. (2017). Understand the Consequences of Public Social Media Use for Work. European Management Journal, 35(5), 595-605. 